\title{
Executive Dysfunction in Cocaine Addiction: Evidence for Discordant Frontal, Cingulate, and Cerebellar Activity
}

\author{
Robert Hester ${ }^{1}$ and Hugh Garavan ${ }^{1,2}$ \\ ${ }^{1}$ Department of Psychology and Institute of Neuroscience, Trinity College Dublin, Dublin 2, Ireland, and ${ }^{2}$ Department of Psychiatry and Behavioral \\ Medicine, Medical College of Wisconsin, Milwaukee, Wisconsin 53226
}

Using a GO-NOGO response inhibition task in which working memory (WM) demands can be varied, we demonstrate that the compromised abilities of cocaine users to exert control over strong prepotent urges are associated with reduced activity in anterior cingulate and right prefrontal cortices, two regions thought to be critical for implementing cognitive control. Furthermore, unlike drug-naive controls, and opposite to the anterior cingulate pattern, cocaine users showed an over-reliance on the left cerebellum, a compensatory pattern previously seen in alcohol addiction. The results indicate that cocaine users find it difficult to inhibit their own actions, particularly when WM demands, which have been shown previously to increase during cue-induced craving for the drug, are increased. The results reveal a neuroanatomical basis for this dysexecutive component to addiction, supporting the suggested importance cognitive functions may play in prolonging abuse or predisposing users toward relapse.

Key words: cocaine; executive function; response inhibition; working memory; addiction; fMRI

\section{Introduction}

Human drug addiction has come to be viewed as a complex process of the brain (Goldstein and Volkow, 2002), in which cognitive factors such as the inability to control one's own behavior in light of the strong motivation to consume a drug are considered critical. A recent hypothesis has argued for the role of executive dysfunction in drug addiction (Lyvers, 2000), in which the effects of cocaine on brain structures that are important to the cognitive control of behavior contribute directly to the addiction process. Repeated use of cocaine is associated with structural (Franklin et al., 2002; Matochik et al., 2003) and metabolic (Ernst et al., 2000) abnormalities in the brain, particularly in prefrontal and midline structures considered important for executive control (Miller and Cohen, 2001), and chronic cocaine users consistently display neuropsychological impairments on tests of executive function (Ardila et al., 1991; Di Sclafani et al., 2002).

Recent functional neuroimaging research examined whether the neural changes that accompany cocaine use contribute to executive dysfunction, finding an association between activation changes and greater difficulty with inhibiting a prepotent response (Bolla et al., 2000, 2001; Goldstein et al., 2001; Kaufman et al., 2003). This effect was particularly evident within the anterior cingulate cortex (ACC), consistent with the postulated effect of cocaine on the mesencephalic dopamine system (which includes the ACC, prefrontal cortex, and orbitofrontal cortex). Cocaine is believed to exert its reinforcing effects by blocking the reuptake of

Received July 6, 2004; revised Sept. 24, 2004; accepted Oct. 3, 2004.

This research was supported by United States Public Health Service Grant DA14100 and General Clinical Research Center Grant M01 RR00058. The assistance of Jacqueline Kaufman, Veronica Dixon, and Kevin Murphy is gratefully acknowledged.

Correspondence should be addressed to Hugh Garavan, Department of Psychology and Institute of Neuroscience, Trinity College Dublin, Dublin 2, Ireland. E-mail: hugh.garavan@tcd.ie.

DOI:10.1523/JNEUROSCI.3321-04.2004

Copyright $\odot 2004$ Society for Neuroscience 0270-6474/04/2411017-06\$15.00/0 dopamine and increasing its concentration in dopamine receptor-rich regions such as the ACC (Koob and Bloom, 1988), and repeated exposure to this hyperdopaminergic state may account for decreased dopamine receptor levels in users and, consequently, decreased metabolism (Volkow et al., 1999).

We hypothesize that the functional changes in the mesencephalic dopamine system that result from chronic cocaine use render the user vulnerable to executive dysfunction. Inhibitory control, as measured by the GO-NOGO task, provides an index of this problem because of the requirement to exert executive control over a prepotent motor response with a neural network of prefrontal and midline [ACC and presupplementary motor area (pre-SMA)] regions. To test this hypothesis further, we adapted a GO-NOGO task to allow for parametric increases in working memory (WM) demands. These demands were of interest because previous studies with cocaine users have suggested that cue-induced ruminative thoughts activate a "WM-like" network of cortical regions (Bonson et al., 2002) and can interfere with WM performance (Grant et al., 1996; Watkins and Brown, 2002; Vreugdenburg et al., 2003), whereas increasing WM demands are known to negatively impact executive control, seemingly because of the requirement for greater top-down control (Bunge et al., 2001; Hester et al., 2004). Our aim was to examine whether increasing WM demands would have a greater negative impact on cocaine users' inhibitory control, with hypoactivity in regions required for top-down control making users particularly vulnerable to inhibitory failures when greater top-down control was required.

\section{Materials and Methods}

Subjects. Fifteen nondrug-using subjects (eight females; mean age, 31; range, 20-40) and 15 active cocaine users (six females; mean age, 40; range, 22-48) participated in the current study. Educational attainment for the two groups was not significantly different ( 13.9 vs 11.5 years). All 


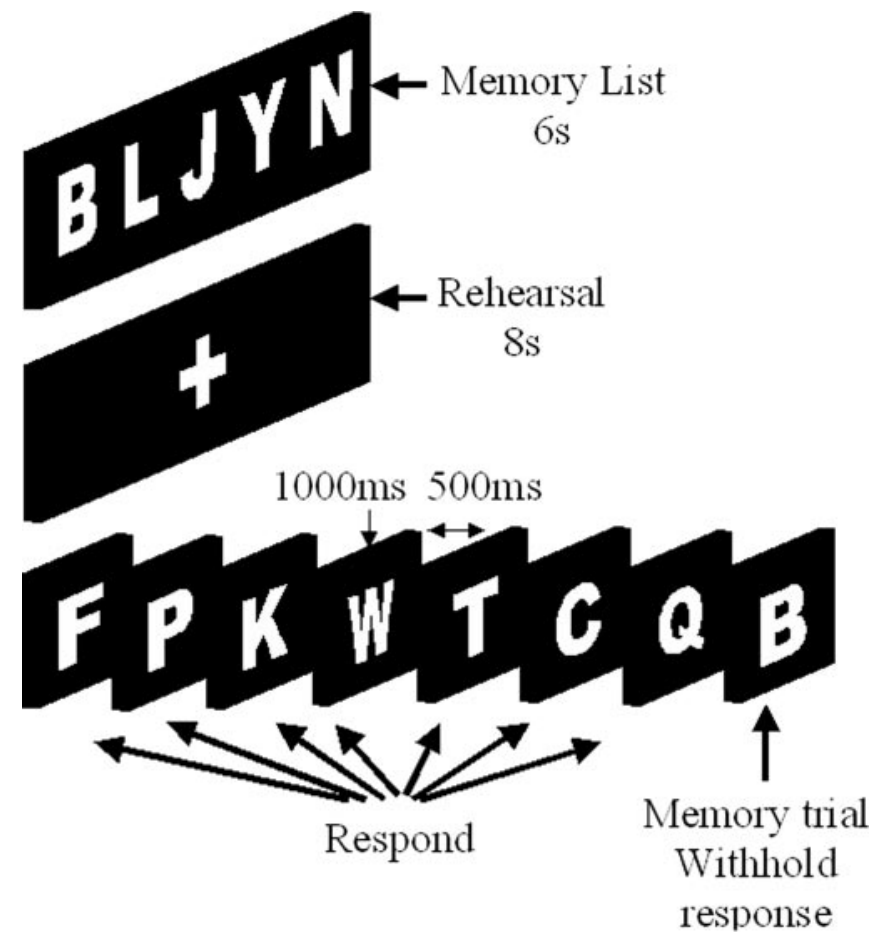

Figure 1. WM load inhibition task design. The design of the task requires participants to withhold a prepotent response to an increasing number of items currently held in WM. At the beginning of the task, a memory list of one, three, or five items was presented. A series of single letters was then presented, and participants were told to press a button if the item had not been part of the memory list ( $88 \%$ of trials) and withhold their response if it had.

of the subjects were right-handed [as determined by the Edinburgh inventory (Oldfield, 1971)] and reported no current or past history of neurological or psychiatric disorders or dependence on any psychoactive substance other than cocaine (for user subjects only), caffeine, or nicotine. Subjects were fully informed of the nature of the research and provided written consent for their involvement in accordance with the Institutional Review Board of the Medical College of Wisconsin. Urine samples were taken from all of the subjects to test for drug use, with all of the nondrug subjects returning negative tests for all drugs and active cocaine users returning positive tests for cocaine or the metabolites of cocaine, indicating that they had used cocaine within the past $72 \mathrm{hr}$. No user displayed overt signs of cocaine intoxication, with the average time since last use reported at $41 \mathrm{hr}$ (range, 12-72 hr). Cocaine user subjects reported using an average of five times per week (range, 1-7) for the past 14 years (range, 5-27 years), spending an average of \$252 (range, 25$1000)$ per week. User subjects who were positive for any drug (on the urine screen) other than cocaine, nicotine, or marijuana were excluded. Twelve individuals from the cocaine user sample reported occasional use of cannabis; the average duration since last use was $15 \mathrm{~d}$, and none had consumed in the $24 \mathrm{hr}$ before scanning. The acute effects of cannabis intoxication on the cognitive performance (including inhibitory control) of occasional users are short-lived (peaking at $2 \mathrm{hr}$ after consumption and lasting up to $8 \mathrm{hr}$ ) and are not present after $24 \mathrm{hr}$ (Fant et al., 1998; Curran et al., 2002), and "light" (once per week) use of cannabis has not been associated with decrements in cognitive test performance (Pope et al., 2001). Eleven subjects (10 cocaine users and one control) also reported regular use of tobacco (mean, 12.5 cigarettes per day). Subjects were not asked to abstain from cigarette smoking, because nicotine craving could potentially confound the behavioral and imaging data (Brody et al., 2002).

Behavioral task. Subjects completed a GO-NOGO inhibition task based on our previous work (Hester and Garavan, 2004; Hester et al., 2004). The WM load inhibitory task (WM-IT) presented a primary inhibitory task, within which a WM load was embedded (Fig. 1). To begin the task, subjects were shown a "memory list" of one, three, or five uppercase letters. The memory list was presented for $6 \mathrm{sec}$ and immediately followed by a rehearsal period of $8 \mathrm{sec}$ that presented a white crosshair on a black background. Participants were instructed during the practice session to use this $8 \mathrm{sec}$ period for rehearsal of the items. A series of 60 decision trials then followed, each lasting $1500 \mathrm{msec}$, including the presentation of a single letter in white font on a black background for 1000 msec and a blank screen for the concluding $500 \mathrm{msec}$. The subject was trained to press a button for each trial featuring a letter that was not part of the memory list (GO trials) and withhold their response for items that were part of the memory list (NOGO trials). The 60 trials included $53 \mathrm{GO}$ trials and seven NOGO trials, which were pseudorandomly placed throughout each run. The high proportion of GO trials creates a prepotency for the button press response that must be overcome when the subject identifies that a letter belonged to the memory list. The advantage of this design is that participants cannot strategically switch between the two tasks in an attempt to improve performance; rather, they are required to use the contents of WM to successfully exert inhibitory control.

Each subject was administered 18 experimental runs, with six runs per memory list size (one, three, or five items), and a single run composed of the $6 \mathrm{sec}$ encoding period, $8 \mathrm{sec}$ rehearsal period, 60 consecutive $1.5 \mathrm{sec}$ decision trials, and a $30 \mathrm{sec}$ concluding rest interval. The order of runs was identical for each participant, with the sequence of presentation counterbalancing memory load requirements (i.e., 1, 3, 5, 3, 5, 1, 5, 3, 1, etc.). At the conclusion of every third run, a longer (unscanned) rest period was provided.

During the previous administrations of the task (Hester and Garavan, 2004), the final trial of a run was followed by asking participants to recall the letters from the current memory list by typing them on the keyboard. No time limit was imposed for this recall period, and letters could be typed in any order. Performance for $>80$ control subjects has indicated average recall for the five item condition to be $>95 \%$. Because of practicalities of magnetic resonance imaging (MRI) administration, this aspect of the task was not administered during the scanner runs of the present study. However, to ensure that group differences between controls' and cocaine users' inhibition performance did not result from poorer WM performance for the latter groups, a subset of cocaine users $(n=7)$ was administered the "memory-recall" version of the WM-IT. The results indicated average recall for the five item condition of $93.54 \%$ for cocaine users.

Functional MRI procedures and analysis. Scanning was conducted on contiguous $7 \mathrm{~mm}$ sagittal slices covering the entire brain from a $1.5 \mathrm{~T}$ General Electric (Milwaukee, WI) Signa scanner using a blipped gradient-echo, echo-planar pulse sequence [echo time (TE), $40 \mathrm{msec}$ repetition time (TR), $2000 \mathrm{msec}$; field of view (FOV), $24 \mathrm{~cm}$; $64 \times 64$ matrix; $3.75 \mathrm{~mm} \times 3.75 \mathrm{~mm}$ in-plane resolution]. High-resolution spoiled gradient-recalled acquisition in a steady state anatomic images (TR, $24 \mathrm{msec}$; TE, $5 \mathrm{msec}$; flip angle, $45^{\circ}$; FOV , $24 \mathrm{~cm}$; thickness, $1.0 \mathrm{~mm}$ with no gap) were acquired after the functional imaging to allow subsequent activation localization and for spatial normalization. Foam padding was used to limit head movements within the coil. Stimuli were back-projected onto a screen at the subject's feet and were viewed with the aid of prism glasses attached to the inside of the radio-frequency head coil. The task was programmed and displayed using E-prime (version 1; Psychology Software Tools, Pittsburgh, PA).

All analyses were conducted using AFNI (analyses of functional neuroimages) software (Cox, 1996). After image reconstruction, the timeseries data were time-shifted using Fourier interpolation to remove differences in slice acquisition times and motion-corrected using threedimensional volume registration (least-squares alignment of three translational and three rotational parameters). Activation outside the brain was also removed using edge-detection techniques. No subjects showed significant residual motion, thus allowing all 30 to be included. Although the stimulus stream was presented at $1.5 \mathrm{~Hz}$, all events of interest were time locked to the beginning of the $2 \mathrm{sec}$ whole-brain volume acquisition during presentation of the task.

To examine the influence of WM demands on inhibitory control, an event-related analysis was performed that estimated the activation separately for inhibitions during each of the WM load conditions. To do this, separate hemodynamic response functions at $2 \mathrm{sec}$ temporal resolution were calculated using deconvolution techniques for successful response 
Table 1. Regions of event-related activation during successful response inhibition (STOPS)

\begin{tabular}{|c|c|c|c|c|c|c|c|c|c|}
\hline \multirow[b]{2}{*}{ Structure } & \multirow[b]{2}{*}{ BA } & \multirow[b]{2}{*}{ HS } & \multirow{2}{*}{$\begin{array}{l}\text { Volume } \\
(\mu \mathrm{l})\end{array}$} & \multicolumn{3}{|c|}{ Center of mass } & \multirow[b]{2}{*}{ Load } & \multirow[b]{2}{*}{ Group } & \multirow[b]{2}{*}{ Group by load interaction } \\
\hline & & & & $x$ & $y$ & $z$ & & & \\
\hline \multicolumn{10}{|l|}{ Frontal lobe } \\
\hline \multirow[t]{2}{*}{ Superior frontal } & $10 / 9$ & $\mathrm{R}$ & 889 & 25 & 48 & 26 & & * & \\
\hline & 9 & $\mathrm{~L}$ & 426 & -30 & 38 & 30 & & & \\
\hline \multirow[t]{6}{*}{ Middle frontal } & $10 / 46$ & $\mathrm{R}$ & 1829 & 38 & 36 & 23 & & & \\
\hline & 6 & $\mathrm{R}$ & 1528 & 28 & 3 & 53 & & & \\
\hline & 6 & $\mathrm{~L}$ & 657 & -23 & -1 & 54 & 个 & & \\
\hline & $9 / 6$ & $\mathrm{R}$ & 597 & 40 & 4 & 38 & & & \\
\hline & 9 & $\mathrm{R}$ & 198 & 38 & 18 & 38 & 个 & & \\
\hline & 6 & $\mathrm{~L}$ & 159 & -39 & -1 & 43 & $\Uparrow$ & & \\
\hline Inferior frontal/insula & $47 / 13$ & $\mathrm{R}$ & 1329 & 39 & 16 & 3 & & & \\
\hline Medial & $6 / 8 / 32$ & $\mathrm{~L}$ & 1074 & -6 & 14 & 46 & 介 & & \\
\hline Pre-SMA & 6 & $\mathrm{R}$ & 1298 & 7 & 6 & 57 & & * & \\
\hline Anterior cingulate & $32 / 24$ & $\mathrm{~L}$ & 1325 & -2 & 33 & 22 & 个 & * & Controls, ^; users,- \\
\hline \multicolumn{10}{|l|}{ Parietal lobe } \\
\hline \multirow[t]{2}{*}{ Inferior parietal } & 40 & $\mathrm{R}$ & 7724 & 40 & -44 & 38 & & & \\
\hline & 40 & L & 2313 & -39 & -56 & 39 & & & \\
\hline Precuneus & 7 & $\mathrm{~L}$ & 335 & -24 & -67 & 40 & 个 & & \\
\hline \multirow[t]{2}{*}{ Cingulate } & 23 & $\mathrm{R}$ & 173 & 4 & -28 & 21 & & & \\
\hline & $23 / 31$ & L & 162 & -2 & -30 & 28 & 个 & & \\
\hline \multicolumn{10}{|l|}{ Temporal lobe } \\
\hline Superior temporal & 39 & $\mathrm{~L}$ & 343 & -52 & -54 & 10 & & & \\
\hline \multirow[t]{2}{*}{ Middle temporal } & 21 & $\mathrm{R}$ & 423 & 55 & -33 & -5 & & & \\
\hline & 20 & L & 166 & -50 & -32 & -9 & & & \\
\hline Fusiform & 37 & L & 205 & -32 & -51 & -8 & & & \\
\hline \multicolumn{10}{|l|}{ Subcortical } \\
\hline Thalamus & & $\mathrm{L}$ & 574 & -1 & -15 & 0 & & & \\
\hline \multirow[t]{2}{*}{ Lentiform } & & $\mathrm{R}$ & 4325 & 17 & 5 & 6 & & & \\
\hline & & $\mathrm{L}$ & 1182 & -21 & 8 & 2 & & & \\
\hline Caudate & & L & 285 & -14 & 1 & 12 & & & \\
\hline \multicolumn{10}{|l|}{ Cerebellum } \\
\hline Culmen & & $\mathrm{L}$ & 1775 & -33 & -49 & -26 & & & Controls, $\Downarrow ;$;users, $\uparrow$ \\
\hline Inferior & & L & 268 & -18 & -62 & -43 & & & \\
\hline Pyramis & & L & 186 & -12 & -68 & -25 & $\Downarrow$ & & Controls, $\Downarrow ;$;users, $\uparrow$ \\
\hline Tonsil & & $\mathrm{R}$ & 160 & 13 & -60 & -32 & & & \\
\hline
\end{tabular}

Positive values for $x, y$, and $z$ coordinates denote, respectively, locations that are right, anterior, and superior relative to the anterior commissure. Arrows in the Load column represent the direction of activation change for clusters found to be sensitive to increasing WM load for the entire sample (significant at $p<0.05$, corrected). Asterisks represent the three clusters demonstrating significantly greater activation for control subjects when compared with cocaine users. Significant interaction effects are represented with directional arrows for each group that indicates the effect of WM load on activation. HS, Hemisphere; $R$, right; L, left.

inhibitions (STOPS) at each load size (designated STOPS1, STOPS3, and STOPS5). Because of the relatively small number of error events, the deconvolved hemodynamic response for errors of commission (ERRORS) included the errors committed over all load sizes. A nonlinear regression program determined the best-fitting gamma-variate function for these impulse-response functions (Cohen, 1997) as described previously (Garavan et al., 1999). The area under the curve of the gammavariate function was expressed as a percentage of the area under the baseline. The baseline for this task was the ongoing trial period (GO trials), with the activation for other periods of the task (i.e., encoding, rehearsal, and rest) censored from the analysis. Therefore, the activation observed during these events represents the activation for the events over and above that required for the ongoing trial period (or GO) responses.

The percentage area (event-related activation) voxels were resampled at $1 \mathrm{~mm}^{3}$ resolution, warped into standard Talairach space (Talairach and Tournoux, 1988), and spatially blurred with a $3 \mathrm{~mm}$ isotropic rms Gaussian kernel. Group activation maps for each load size were determined with one-sample $t$ tests against the null hypothesis of zero eventrelated activation changes (i.e., no change relative to baseline). Significant voxels passed a voxelwise statistical threshold $(t=5.226 ; p=$ $0.0001)$ and were required to be part of a larger $87 \mu \mathrm{l}$ cluster of contiguous significant voxels. Thresholding was determined through Monte Carlo simulations and resulted in a $1 \%$ probability of a cluster surviving because of chance. The separate activation maps were then combined, deriving an OR map of STOPS that included all voxels of activation indicated as significant from any of the constituent maps (STOPS1, STOPS3, or STOPS5). The mean activation for clusters in the OR map was calculated for the purposes of a region of interest analysis, and these data were used for a repeated-measures comparison between load size conditions (Table 1), corrected using a modified Bonferroni procedure for multiple comparisons (Keppel, 1991). The localization of the activation clusters to cortical regions was based on information provided by the Talairach Daemon in AFNI (version 2.5), although these were rechecked using the singlepoint processing feature on the Talairach Daemon Database (version 1.1) provided by the Research Imaging Center at the University of Texas Health Science Center. The Brodmann designation provided for activation clusters represents the area where the center of mass of a cluster fell, although when visual inspection indicated substantial portions of a cluster falling in other regions, additional designations were provided.

\section{Results}

Consistent with previous studies, WM load exerted a negative impact on inhibition (Fig. 2). Increasing memory load significantly reduced the number of correct inhibitions $\left(F_{(2,56)}=53.94\right.$; $p<0.01$; pairwise comparisons confirmed significant differences between performance at all three load levels) and significantly increased GO reaction time $(\mathrm{RT})\left(F_{(2,56)}=\right.$ $188.31 ; p<0.0001)$. A significant group $\left(F_{(1,28)}=15.03 ; p<0.01\right)$ and group by load interaction $\left(F_{(2,56)}=3.34 ; p<0.05\right)$ indicated that the inhibition performance of controls was significantly better than cocaine users, with the advantage increasing with greater WM demands. The absence of group $\left(F_{(1,28)}=0.42 ; p=0.52\right)$ and interaction effects $\left(F_{(2,56)}=1.33 ; p=\right.$ 0.27) for GO RT also suggests that the poorer inhibitory performance of users was not the result of differences in response prepotency. Given the group differences in age and gender, a repeated-measures ANOVA examining the influence of these demographic variables on inhibitory control performance was performed, using WM load (three levels) as the within-subjects variable, group (cocaine users vs controls) as the between-groups variable, and both age and sex as covariates. The results supported the original findings of main effects for group $\left(F_{(1,28)}=11.89 ; p<0.01\right)$ and group by load interaction $\left(F_{(2,56)}=3.26 ; p<0.05\right)$. Neither age nor gender significantly mediated the influence of group on behavioral performance.

During correct inhibition events, several regions were found to be sensitive to WM load, including increased activation in the right [Brodmann areas (BAs) 9/6] and left (BA 6) middle frontal gyri, left medial frontal cortex (BAs 6/8/32), left precuneus (BA 7 ), and anterior (BAs 32/24) and posterior cingulate (BAs 23/31) cortices (Table 1 ). Few clusters of activation significantly differentiated control subjects from cocaine users (Fig. 3A,B), with greater activation for controls in the ACC, pre-SMA, and right superior frontal gyrus. The importance of ACC activity to behavioral performance was supported by the significant positive correlation $(r=0.44 ; p<0.01)$ between ACC activity and correct inhibitions during the five item condition of the current study. 


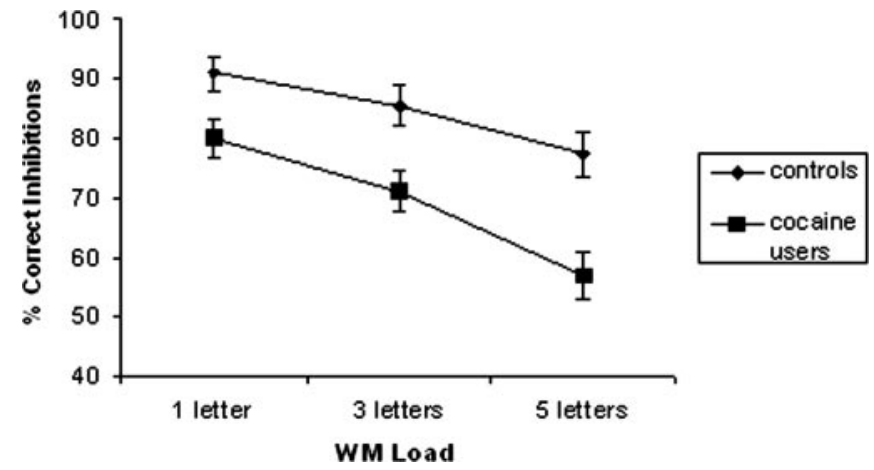

Figure 2. Control and cocaine users' performance on the GO-NOGO inhibition task with different WM loads.

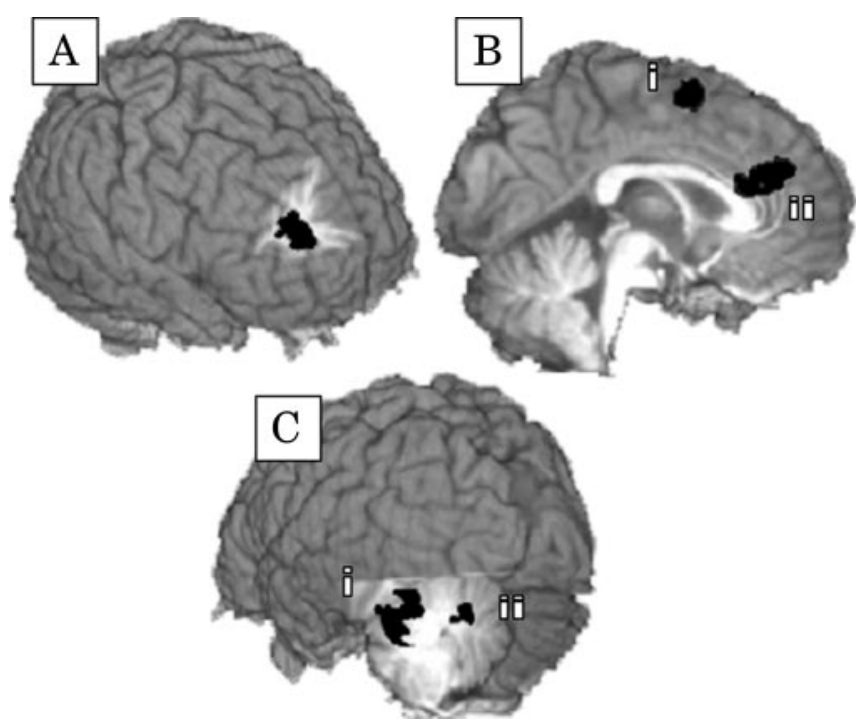

Figure 3. The cortical regions that indicated significantly greater levels of activation for control subjects when compared with cocaine users include the right superior frontal gyrus ( $A$, BAs 10/9; Talairach coordinates, 25, 48, 26), right pre-SMA (Bi, BA 6; Talairach coordinates, 7, 5 57 ), and left ACC (Bii, BAs 32/24; Talairach coordinates, $-2,32,22$ ). The cortical regions showing significant interactions between load and group include the $A C C$ (Bii) and two regions in the left cerebellum ( $C$, Talairach coordinates, $-33,-49,-25$; (ii, Talairach coordinates, -12 , $-68,-25)$.

Activity in this region also indicated a significant interaction between group and WM load $\left(F_{(2,56)}=3.63\right.$; $\left.p<0.05\right)$ with the level of activation for control subjects significantly increasing with greater WM demands $\left(F_{(2,28)}=10.51 ; p<0.001\right)$ but remaining static for cocaine users $\left(F_{(2,56)}=0.64 ; p>0.05\right)$.

Accompanying the nonresponsiveness of the ACC for cocaine users was over-responsiveness of their left cerebellum to increasing WM demands. Activity in two clusters in the left culmen (Fig. $3 \mathrm{Ci}$ ) and left pyramis (Fig. 3Cii) indicated a significant interaction between group and load $\left(F_{(2,56)}=4.60, p<0.01 ; F_{(2,56)}=\right.$ $4.43, p<0.01$, respectively) with significant increases in cerebellar activity in response to increasing WM demands for cocaine users only. The level of activity in these two cerebellar regions was consequential to inhibitory performance, demonstrating significant negative correlations with performance $(r=-0.54, p<$ $0.005 ; r=-0.51, p<0.005$ ). These correlations persisted when examining just the cocaine user sample $(n=15 ; r=-0.47, p<$ $0.08 ; r=-0.48, p<0.07)$; however, they only approached significance because of the reduced power afforded by the smaller sample size.

\section{Discussion}

Consistent with previous studies (Bunge et al., 2001; de Fockert et al., 2001; Hester et al., 2004), increasing WM demands resulted in significantly poorer response inhibition performance and required greater activation in prefrontal and midline regions for success. We have argued previously, on the basis of modeling from authors such as Miller and Cohen (2001), that the increased WM-related activation of prefrontal regions during inhibition reflects a greater requirement for top-down cognitive control. As the number of items requiring a "withhold" response increases in the present task, more top-down control is required to enact these withholds in the face of a stronger but ultimately taskirrelevant response (the prepotent response). That ACC activity during correct inhibitions also increased with greater WM demands may speak to the proposed reciprocal relationship with prefrontal cortices (MacDonald et al., 2000; Kerns et al., 2004) or indicate that this activity is engaged by particularly difficult executive tasks (Paus, 2001; Garavan et al., 2002). Interestingly, the present results also provide some support for the recent suggestion from Brass and von Cramon (2004) that the left inferior frontal junction, anatomically separable to prefrontal regions, is critical to cognitive control. During correct inhibitions, a cluster $(x=-39, y=-1, z=43)$ in close proximity to the area identified by Brass and von Cramon $(x=-37, y=5, z=32)$, was found to have greater activation with increasing WM loads.

Cocaine users had significantly greater difficulty responding to the requirement for top-down control, because their responseinhibition performance was significantly poorer than control subjects, an effect that was compounded by greater WM demands. The inability of users to adjust to these demands coincided with static ACC activity, remaining unchanged despite control performance indicating that such an increase is critical to coping with the greater WM demands. The small body of neuroimaging literature examining executive function in cocaine users has previously identified relative hypoactivity in the ACC (Bolla et al., 2000, 2001; Kaufman et al., 2003), although the present study also found significantly lower activation in the right prefrontal (BA 9) and pre-SMA regions. This pattern would appear to make cocaine users particularly vulnerable to dysexecutive problems, because these regions are commonly implicated in studies of executive function (Carter et al., 1999; Bush et al., 2000; Duncan and Owen, 2000; Paus, 2001; Ullsperger and von Cramon, 2001; Braver et al., 2002).

The unexpected pattern of cerebellar activation identified during response inhibition, in which cocaine users showed increases and controls showed decreases with greater WM demands, may be consistent with both animal and human studies suggesting that cocaine has a significant influence on cerebellar function. Systemically administered cocaine has been shown to substantially alter the functioning of the rat cerebellum (JimenezRivera et al., 2000), and the human cerebellum is one of the most sensitive brain regions to cocaine administration (Volkow et al., 2003). This sensitivity is also increased when the drug is expected (argued to represent a conditioned response), a hypothesis supported by imaging studies indicating cerebellar activation in users exposed to cocaine cues (Grant et al., 1996; Bonson et al., 2002).

Anatomical, physiological, and functional imaging studies suggest that the cerebellum contributes to higher-order cognitive functions (Raymond et al., 1996; Parkins, 1997; Schmahmann and Sherman, 1998; Desmond, 2001; Heyder et al., 2004), with discrete damage to the cerebellum resulting in impairment of executive functions and working memory and in personality 
changes such as disinhibited and inappropriate behavior. Increased cerebellar activity during cognition has also been identified in schizophrenia (Meyer-Lindenberg et al., 2001; Schlosser et al., 2003), where poor working memory performance was accompanied by patterns of functional connectivity suggesting overreliance on the cerebellum by patients. A compensatory pattern of activity has also been demonstrated in alcoholics, in whom equivalent working memory performance was supported by relative increases in right cerebellar regions (Desmond et al., 2003), suggested to be supporting reduced activity in the left prefrontal cortex, particularly when task demands were increased. Desmond et al. (2003) highlight that cerebellar activation often occurs in tandem with contralateral frontal lobe activation, consistent with the neuroanatomy indicating contralateral corticopontocerebellar projections within the monkey brain (Brodal, 1979; Schmahmann and Pandya, 1997).

The hypothesis that the increased left cerebellar activity identified here might compensate for diminished right prefrontal activity in cocaine users does have some support, because the right prefrontal region was the only nonmidline region to show relative hypoactivity in cocaine users. As the greater demands for cognitive control were required in the current task, control subjects increased activation in cingulate and right prefrontal regions, whereas cocaine users, perhaps because of cortical changes, increased activity in the left cerebellum. That this increased cerebellar activity correlated with poor inhibitory performance may not necessarily suggest that it was detrimental; rather, it may indicate that those subjects who found the task most difficult were more likely to activate the cerebellum. The cerebellum has been implicated previously in responding to greater WM loads (Desmond et al., 1997); however, it has consistently been a left frontal-right superior cerebellar relationship involved in the articulatory process of verbal working memory. That left cerebellar regions were involved here appears to suggest that this activation was responding not to greater articulatory demands but instead to the greater demands WM load placed on inhibitory control. These increased demands on inhibitory control did require greater right prefrontal activation in controls, a region typically involved in GO-NOGO inhibition tasks (Konishi et al., 1999; Liddle et al., 2001; Garavan et al., 2002; Mostofsky et al., 2003; Rubia et al., 2003) and inhibitory control generally (Aron et al., 2004). That increased difficulty for inhibition required greater right prefrontal activity would also appear consistent with why cocaine users showed greater left cerebellar activity, if indeed the contralateral compensatory frontal-cerebellar hypothesis is responsible here.

The results of the present study indicate for the first time that the difficulty cocaine users have with inhibitory control, particularly when high levels of cognitive control are required, relates directly to a reduced capacity for modulating activity in the ACC and prefrontal regions. Responding to greater requirements for cognitive control is widely argued to rely on a reciprocal relationship between these regions, with the ACC detecting fluctuations in the need for control that are signaled to the prefrontal cortices for implementation. This relationship would account for cocaine users' difficulty with the current task, because increasing cognitive control requirements appear to have placed greater demands on an already under-responsive monitoring mechanism, which was in turn signaling an impaired right prefrontal cortex to implement a more difficult action.

That cocaine users find it difficult to inhibit their own actions, particularly when WM demands of the type experienced during cue-induced craving for the drug are increased, appears entirely consistent with the sequelae of cocaine addiction. Research suggests that cue-related cocaine craving involves the activation of a network of cortical regions involved in the engagement of attention and that the subsequent ruminations also involve the frontoparietal network seen in WM rehearsal (Grant et al., 1996; Maas et al., 1998; Childress et al., 1999; Garavan et al., 2000; Kilts et al., 2001). Although the relationship between craving for cocaine and relapse during abstinence is less than straightforward (Miller and Gold, 1994; Bordnick and Schmitz, 1998; Weiss et al., 2001), users typically report that cravings occur before and during the period of highly ritualized and automatic drug-taking behavior that results from an impulse of unknown origin (Miller and Gold, 1994). The results of the present study suggest that the effects of cocaine on brain regions critical to cognitive control may directly contribute to the vulnerability of chronic users to these impulsive and automatic behaviors, particularly during periods of craving for the drug.

\section{References}

Ardila A, Rosselli M, Strumwasser S (1991) Neuropsychological deficits in chronic cocaine abusers. Int J Neurosci 57:73-79.

Aron AR, Robbins TW, Poldrack RA (2004) Inhibition and the right inferior frontal cortex. Trends Cogn Sci 8:170-177.

Bolla KI, Ernst J, Mouratidis F, Funderbunk J, Matochik JA, Kurian V, Bragg J, Cadet JL, Kimes AS, London ED (2000) Reduced brain activation in chronic cocaine abusers during performance on the Stroop color-word interference task. Soc Neurosci Abstr 26:482.12.

Bolla KI, Ernst M, Mouratidis M, Matochik JA, Contoreggi C, Kurian V, Cadet JL, Kimes AS, Eldreth D, London ED (2001) Reduced cerebral blood flow in anterior cingulate cortex (ACC) during Stroop performance in chronic cocaine users. Hum Brain Mapp 13:772.

Bonson KR, Grant SJ, Contoreggi CS, Links JM, Metcalfe J, Weyl HL, Kurian V, Ernst M, London ED (2002) Neural systems and cue-induced cocaine craving. Neuropsychopharmacology 26:376-386.

Bordnick PS, Schmitz JM (1998) Cocaine craving: an evaluation across treatment phases. J Subst Abuse 10:9-17.

Brass M, von Cramon DY (2004) Decomposing components of task preparation with functional magnetic resonance imaging. J Cogn Neurosci 16:609-620.

Braver TS, Cohen JD, Barch DM (2002) The role of prefrontal cortex in normal and disordered cognitive control: a cognitive neuroscience perspective. In: Principles of frontal lobe function (Stuss DTK, Robert T, eds), pp 428-447. London: Oxford UP.

Brodal P (1979) The pontocerebellar projection in the rhesus monkey: an experimental study with retrograde axonal transport of horseradish peroxidase. Neuroscience 4:193-208.

Brody AL, Mandelkern MA, London ED, Childress AR, Lee GS, Bota RG, Ho ML, Saxena S, Baxter Jr LR, Madsen D, Jarvik ME (2002) Brain metabolic changes during cigarette craving. Arch Gen Psychiatry 59:1162-1172.

Bunge SA, Ochsner KN, Desmond JE, Glover GH, Gabrieli JD (2001) Prefrontal regions involved in keeping information in and out of mind. Brain 124:2074-2086.

Bush G, Luu P, Posner MI (2000) Cognitive and emotional influences in anterior cingulate cortex. Trends Cogn Sci 4:215-222.

Carter CS, Botvinick MM, Cohen JD (1999) The contribution of the anterior cingulate cortex to executive processes in cognition. Rev Neurosci 10:49-57.

Childress AR, Mozley PD, McElgin W, Fitzgerald J, Reivich M, O’Brien CP (1999) Limbic activation during cue-induced cocaine craving. Am J Psychiatry 156:11-18.

Cohen MS (1997) Parametric analysis of fMRI data using linear systems methods. NeuroImage 6:93-103.

Cox RW (1996) AFNI: software for analysis and visualization of functional magnetic resonance neuroimages. Comput Biomed Res 29:162-173.

Curran HV, Brignell C, Fletcher S, Middleton P, Henry J (2002) Cognitive and subjective dose-response effects of acute oral Delta-sup-9tetrahydrocannabinol (THC) in infrequent cannabis users. Psychopharmacology (Berl) 164:61-70. 
de Fockert JW, Rees G, Frith CD, Lavie N (2001) The role of working memory in visual selective attention. Science 291:1803-1806.

Desmond JE (2001) Cerebellar involvement in cognitive function: evidence from neuroimaging. Int Rev Psychiatry 13:283-294.

Desmond JE, Gabrieli JD, Wagner AD, Ginier BL, Glover GH (1997) Lobular patterns of cerebellar activation in verbal working-memory and finger-tapping tasks as revealed by functional MRI. J Neurosci 17:9675-9685.

Desmond JE, Chen SH, DeRosa E, Pryor MR, Pfefferbaum A, Sullivan EV (2003) Increased frontocerebellar activation in alcoholics during verbal working memory: an fMRI study. NeuroImage 19:1510-1520.

Di Sclafani V, Tolou-Shams M, Price LJ, Fein G (2002) Neuropsychological performance of individuals dependent on crack-cocaine, or crackcocaine and alcohol, at 6 weeks and 6 months of abstinence. Drug Alcohol Depend 66:161-171.

Duncan J, Owen AM (2000) Common regions of the human frontal lobe recruited by diverse cognitive demands. Trends Neurosci 23:475-483.

Ernst T, Chang L, Oropilla G, Gustavson A, Speck O (2000) Cerebral perfusion abnormalities in abstinent cocaine abusers: a perfusion MRI and SPECT study. Psychiatry Res 99:63-74.

Fant RV, Heishman SJ, Bunker EB, Pickworth WB (1998) Acute and residual effects of marijuana in humans. Pharmacol Biochem Behav 60:777-784

Franklin TR, Acton PD, Maldjian JA, Gray JD, Croft JR, Dackis CA, O'Brien CP, Childress AR (2002) Decreased gray matter concentration in the insular, orbitofrontal, cingulate, and temporal cortices of cocaine patients. Biol Psychiatry 51:134-142.

Garavan H, Ross TJ, Stein EA (1999) Right hemispheric dominance of inhibitory control: an event-related functional MRI study. Proc Natl Acad Sci USA 96:8301-8306.

Garavan H, Pankiewicz J, Bloom A, Cho JK, Sperry L, Ross TJ, Salmeron BJ, Risinger R, Kelley D, Stein EA (2000) Cue-induced cocaine craving: neuroanatomical specificity for drug users and drug stimuli. Am J Psychiatry $157: 1789-1798$.

Garavan H, Ross TJ, Murphy K, Roche RA, Stein EA (2002) Dissociable executive functions in the dynamic control of behavior: inhibition, error detection, and correction. NeuroImage 17:1820-1829.

Goldstein RZ, Volkow ND (2002) Drug addiction and its underlying neurobiological basis: neuroimaging evidence for the involvement of the frontal cortex. Am J Psychiatry 159:1642-1652.

Goldstein RZ, Volkow ND, Wang GJ, Fowler JS, Rajaram S (2001) Addiction changes orbitofrontal gyrus function: involvement in response inhibition. NeuroReport 12:2595-2599.

Grant S, London ED, Newlin DB, Villemagne VL, Liu X, Contoreggi C, Phillips RL, Kimes AS, Margolin A (1996) Activation of memory circuits during cue-elicited cocaine craving. Proc Natl Acad Sci USA 93:12040-12045.

Hester R, Garavan H (2004) Working memory and executive function: the influence of content and load on the control of attention. Mem Cognit, in press.

Hester R, Murphy K, Garavan H (2004) Beyond common resources: the cortical basis for resolving task interference. NeuroImage 23:202-212.

Heyder K, Suchan B, Daum I (2004) Cortico-subcortical contributions to executive control. Acta Psychol (Amst) 115:271-289.

Jimenez-Rivera CA, Segarra O, Jimenez Z, Waterhouse BD (2000) Effects of intravenous cocaine administration on cerebellar Purkinje cell activity. Eur J Pharmacol 407:91-100.

Kaufman JN, Ross TJ, Stein EA, Garavan H (2003) Cingulate hypoactivity in cocaine users during a GO-NOGO task as revealed by event-related fMRI. J Neurosci 23:7839-7843.

Keppel G (1991) Design and analysis: a researcher's handbook. Englewood Cliffs, NJ: Prentice Hall.

Kerns JG, Cohen JD, MacDonald III AW, Cho RY, Stenger VA, Carter CS (2004) Anterior cingulate conflict monitoring and adjustments in control. Science 303:1023-1026.

Kilts CD, Schweitzer JB, Quinn CK, Gross RE, Faber TL, Muhammad F, Ely TD, Hoffman JM, Drexler KP (2001) Neural activity related to drug craving in cocaine addiction. Arch Gen Psychiatry 58:334-341.

Konishi S, Nakajima K, Uchida I, Kikyo H, Kameyama M, Miyashita Y (1999) Common inhibitory mechanism in human inferior prefrontal cortex revealed by event-related functional MRI. Brain 122:981-991.

Koob GF, Bloom FE (1988) Cellular and molecular mechanisms of drug dependence. Science 242:715-723.
Liddle PF, Kiehl KA, Smith AM (2001) Event-related fMRI study of response inhibition. Hum Brain Mapp 12:100-109.

Lyvers M (2000) "Loss of control" in alcoholism and drug addiction: a neuroscientific interpretation. Exp Clin Psychopharmacol 8:225-249.

Maas LC, Lukas SE, Kaufman MJ, Weiss RD, Daniels SL, Rogers VW, Kukes TJ, Renshaw PF (1998) Functional magnetic resonance imaging of human brain activation during cue-induced cocaine craving. Am J Psychiatry 155:124-126.

MacDonald III AW, Cohen JD, Stenger VA, Carter CS (2000) Dissociating the role of the dorsolateral prefrontal and anterior cingulate cortex in cognitive control. Science 288:1835-1838.

Matochik JA, London ED, Eldreth D, Cadet JL, Bolla KI (2003) Frontal cortical tissue composition in abstinent cocaine abusers: a magnetic resonance imaging study. NeuroImage 19:1095-1102.

Meyer-Lindenberg A, Poline JB, Kohn PD, Holt JL, Egan MF, Weinberger DR, Berman KF (2001) Evidence for abnormal cortical functional connectivity during working memory in schizophrenia. Am J Psychiatry 158:1809-1817.

Miller E, Cohen JD (2001) An integrative theory of prefrontal cortex function. Annu Rev Neurosci 24:167-202.

Miller NS, Gold MS (1994) Dissociation of "conscious desire" (craving) from and relapse in alcohol and cocaine dependence. Ann Clin Psychiatry 6:99-106.

Mostofsky SH, Schafer JG, Abrams MT, Goldberg MC, Flower AA, Boyce A, Courtney SM, Calhoun VD, Kraut MA, Denckla MB, Pekar JJ (2003) fMRI evidence that the neural basis of response inhibition is taskdependent. Cognit Brain Res 17:419-430.

Oldfield RC (1971) The assessment and analysis of handedness: the Edinburgh inventory. Neuropsychologia 9:97-113.

Parkins EJ (1997) Cerebellum and cerebrum in adaptive control and cognition: a review. Biol Cybern 77:79-87.

Paus T (2001) Primate anterior cingulate cortex: where motor control, drive and cognition interface. Nat Rev Neurosci 2:417-424.

Pope Jr HG, Gruber AJ, Hudson JI, Huestis MA, Yurgelun-Todd D (2001) Neuropsychological performance in long-term cannabis users. Arch Gen Psychiatry 58:909-915.

Raymond JL, Lisberger SG, Mauk MD (1996) The cerebellum: a neuronal learning machine? Science 272:1126-1131.

Rubia K, Smith AB, Brammer M, Taylor E (2003) Right inferior prefrontal cortex mediates response inhibition while mesial prefrontal cortex is responsible for error detection. NeuroImage 20:351-358.

Schlosser R, Gesierich T, Kaufmann B, Vucurevic G, Hunsche S, Gawehn J, Stoeter P (2003) Altered effective connectivity during working memory performance in schizophrenia: a study with fMRI and structural equation modeling. NeuroImage 19:751-763.

Schmahmann JD, Pandya DN (1997) Anatomic organization of the basilar pontine projections from prefrontal cortices in rhesus monkey. J Neurosci 17:438-458.

Schmahmann JD, Sherman JC (1998) The cerebellar cognitive affective syndrome. Brain 121:561-579.

Talairach J, Tournoux P (1988) Co-planar stereotaxic atlas of the human brain. New York: Thieme.

Ullsperger M, von Cramon DY (2001) Subprocesses of performance monitoring: a dissociation of error processing and response competition revealed by event-related fMRI and ERPs. NeuroImage 14:1387-1401.

Volkow ND, Fowler JS, Wang GJ (1999) Imaging studies on the role of dopamine in cocaine reinforcement and addiction in humans. J Psychopharmacol 13:337-345.

Volkow ND, Wang GJ, Ma Y, Fowler JS, Zhu W, Maynard L, Telang F, Vaska P, Ding YS, Wong C, Swanson JM (2003) Expectation enhances the regional brain metabolic and the reinforcing effects of stimulants in cocaine abusers. J Neurosci 23:11461-11468.

Vreugdenburg L, Bryan J, Kemps E (2003) The effect of self-initiated weight-loss dieting on working memory: the role of preoccupying cognitions. Appetite 41:291-300.

Watkins E, Brown RG (2002) Rumination and executive function in depression: an experimental study. J Neurol Neurosurg Psychiatry 72:400-402.

Weiss F, Ciccocioppo R, Parsons LH, Katner S, Liu X, Zorrilla EP, Valdez GR, Ben-Shahar O, Angeletti S, Richter RR (2001) Compulsive drug-seeking behavior and relapse. Neuroadaptation, stress, and conditioning factors. Ann NY Acad Sci 937:1-26. 